\title{
Estigma do nutricionista com obesidade no mundo do trabalho
}

\author{
Stigma of obese dietitians \\ in the work world
}

Kênya Lima de ARAÚJO'

Paulo Gilvane Lopes PENA ${ }^{1}$

Maria do Carmo Soares de FREITAS ${ }^{1}$

Rosa Wanda DIEZ-GARCIA²

R E S U M O

\section{Objetivo}

Este estudo analisa narrativas de nutricionistas mulheres, com obesidade e sua relação com o trabalho, a vida social e a obesidade.

\section{Métodos}

A abordagem qualitativa com entrevistas semiestruturadas apresenta análises na perspectiva hermenêutica das narrativas de 11 nutricionistas da cidade de Salvador, Bahia.

\section{Resultados}

A pesquisa revela que esses sujeitos vivem experiências de estigma e sofrimento no trabalho e em outras relações sociais. Elas são excluídas do trabalho porque a obesidade não é compatível com a atuação prescritora e normatizadora de corpos do nutricionista.

\section{Conclusão}

O estudo expõe o conflito de estar obesa nessa categoria que representa o próprio antagonismo à obesidade.

Palavras-chave: Estigma social. Nutricionista. Obesidade.

\section{A B S T R A C T}

\section{Objective}

This study aims to analyze the narratives of obese female dietitians and their relationship with work, social life, and obesity.

1 Universidade Federal da Bahia, Faculdade de Medicina, Programa de Pós-Graduação em Saúde, Ambiente e Trabalho. Largo do Terreiro de Jesus, s/n., Centro Histórico, 40025-010, Salvador, BA, Brasil. Correspondência para/Correspondence to: PGL PENA. E-mail: <pena@ufba.br>

${ }^{2}$ Universidade de São Paulo, Faculdade de Medicina de Ribeirão Preto, Departamento de Clínica Médica. Ribeirão Preto, SP, Brasil. 


\section{Methods}

This qualitative approach with semi-structured interviews presents analysis from the hermeneutic perspective of eleven dietitians from the city of Salvador, Bahia.

\section{Results}

This study found that these subjects are stigmatized and suffer at their workplace and other social settings. They are despised at work because obesity does not combine with the expected prescriptive and regulatory role of a dietitian.

\section{Conclusion}

This study exposes the conflict associated with being overweight in this field, which is antagonistic to obesity.

Keywords: Social stigma. Nutritionists. Obesity.

\section{N T R O D U Ç Ã O}

O trabalho assegura a sobrevivência por gerar renda e deve ser para o trabalhador "uma relação social, histórica e intersubjetiva"(p.14)'. Nesse sentido, importa nas relações de trabalho cuidar dos indivíduos e considerar sua realidade e seus sentimentos.

Este estudo discute a complexidade do trabalho de nutricionistas com obesidade e a implicação de seus saberes e relações de poder no campo de atuação. Com isso, trata da necessária aproximação com a dimensão cultural do processo saúde-doença para tornar possível a compreensão de signos que podem revelar saúde ou doença para esses sujeitos.

Santos \& Salles ${ }^{2}$ afirmam que a disciplina imposta ao corpo na atualidade advém de uma necessidade de aprovação social. Assim, a obesidade como construção sociocultural e ideológica questiona como padrões morais, políticos e biomédicos contribuem para que esse agravo se torne um problema de ordem social ${ }^{3}$. O trabalho se constitui uma importante dimensão da vida, e, no contexto deste estudo, discute-se o lugar da "pessoa obesa" 4 . Outra pesquisa enfatiza que os sujeitos com obesidade têm menor inserção no mercado de trabalho, mais dificuldade de encontrar emprego e, quando empregados, sofrem mais discriminação ${ }^{3}$.

Problematiza-se aqui o sofrimento do nutricionista que precisa governar o corpo dentro do que defende a racionalidade médica vigente, de modo a atender a imagem que lhe é socialmente requerida e desejada: para a sociedade o corpo medido de um nutricionista deve atender aos padrões antropométricos requeridos pela ciência.

A teoria das relações entre o normal e o patológico considera este último com variações quantitativas de fenômenos fisiológicos ${ }^{5}$. Canguilhem ${ }^{5}$, filósofo e médico, estudioso de epistemologia e história da ciência, afirma que a distinção entre o normal e o patológico é puramente quantitativa para fenômenos orgânicos: o que permite compreender que a obesidade é um desvio do parâmetro estético e do antropométrico considerados normais. Acredita-se que deriva daí uma imagem negativa associada ao corpo gordo que dissemina sofrimento nas mulheres pesquisadas.

Estudo sobre gênero e obesidade ${ }^{6}$ mostra que ao não apresentar um corpo socialmente valorizado, a mulher sente um mal-estar subjetivo devido ao estigma ${ }^{7}$ que é traduzido como falência moral e falta de saúde. Para as nutricionistas pesquisadas, o gordo, ao violar a norma social vigente, experimenta dificuldades em seu meio social, além das atividades profissionais ficarem prejudicadas por causa do preconceito. O obeso desvalorizado e repelido pelo peso do olhar estético do outro ${ }^{8}$ traz a obesidade como um estigma social significativo. Assim, a representação da obesidade como doença que incapacita para o trabalho é difundida?.

Helman ${ }^{10}$ afirma que a forma e o tamanho do corpo comunicam informações sobre a ocu- 
pação dos sujeitos, pois cada profissão possui um modo socialmente aceito de controle do corpo. Pode-se entender que a nutricionista que carrega um corpo obeso tem consigo esta carga de estigma ampliada, possibilitando o desencadeamento de sofrimento pelo insucesso no controle do próprio corpo, uma vez que o sistema social lhe impõe a comprovar sua capacidade de profissional especializado em manter o padrão corporal antropométrico considerado normal.

Neste estudo, a nutricionista com obesidade atribui valores simbólicos ao seu corpo inscritos nas associações entre alimento e mundo do trabalho. É hipótese deste estudo que nutricionistas com obesidade têm dificuldade de inserção no mercado de trabalho, em especial no campo da nutrição clínica, pelo fato de a obesidade gerar dúvidas quanto a sua capacidade técnica. O objetivo desta pesquisa é analisar narrativas de nutricionistas nessa condição e sua relação com o trabalho.

\section{MÉ T O D O S}

Trata-se de uma pesquisa com abordagem qualitativa, realizada no ano de 2014, na cidade de Salvador (BA), nos espaços de trabalho de nutricionistas mulheres com obesidade. As entrevistas foram realizadas em locais de trabalho como hospitais, restaurantes, indústrias, clínicas, salas de aula ou em seus próprios domicílios, quando o local era indicado por elas como o mais conveniente. Trabalhadoras de instituições públicas e/ou privadas, as nutricionistas entrevistadas atuavam nos diversos campos pertinentes à profissão.

Foram estabelecidos como critérios de inclusão: ter a profissão de nutricionista, ser do sexo feminino, ser/sentir-se obesa, atuar/ter atuado no campo da nutrição, aceitar participar do estudo e assinar o Termo de Consentimento Livre e Esclarecido.

Para a identificação de informantes-chave, as nutricionistas entrevistadas indicavam outras colegas, constituindo assim uma seleção entre as pesquisadas ${ }^{11}$. Esse processo ocorreu até a verificação da intersubjetividade nas entrevistas, que foram consideradas satisfatórias para a investigação com a similaridade das informações ${ }^{12}$. Nesse sentido, buscaram-se os significados da obesidade para as nutricionistas na tentativa de compreender como esses sujeitos interpretam essa enfermidade, considerando aspectos relevantes de sua inserção no mundo social e do trabalho.

Para a coleta de dados, foram realizadas e gravadas entrevistas em profundidade, individuais, para garantir a integralidade da fala das entrevistadas, seguidas de transcrição na íntegra dos relatos obtidos. O instrumento de coleta de dados, um roteiro de entrevista semiestruturada, possibilitou um diálogo aberto com as entrevistadas e a aproximação com a pesquisadora.

As entrevistas foram realizadas durante um mês, em sessão única, com duração média de 45 minutos, com um total de 11 participantes, cujos nomes aqui empregados são fictícios a fim de manter preservada a real identidade. As entrevistadas tinham idade entre 30 e 62 anos, com tempo médio de 5 anos trabalhando na área.

$\mathrm{Na}$ análise das narrativas, foi utilizada a abordagem hermenêutica, que permite uma interpretação da realidade a partir de seu contexto sociocultural ${ }^{13,14}$. As interpretações e a escolha dos eixos temáticos obtidos das narrativas foram realizadas com as conexões entre os significantes relacionados à obesidade e os assuntos do trabalho referidos. Os significantes foram destacados e agrupados em categorias que revelaram similitudes e/ou diversidades da obesidade. Neste estudo, para aproximar a realidade social dessas pessoas, os termos obeso e gordo foram considerados sinônimos: eles representam a linguagem ética das ciências naturais e a êmica própria do mundo pessoal e cotidiano.

A pesquisa foi aprovada pelo Comitê de Ética em Pesquisa da Faculdade de Medicina da Universidade Federal da Bahia em 4 de setembro de 2013, sob o n 383.530. Considerou-se a Resolução n 466/12 do Conselho Nacional de Saúde. 


\section{RESULTADOSE DISCUSSÃO}

Para entender como essas mulheres dão significado à experiência da obesidade no mundo do trabalho faz-se necessário um diálogo entre as ciências da saúde, humanas e sociais. Adiante, vê-se que a obesidade, por se tratar de uma enfermidade crônica e de difícil tratamento, gera nas nutricionistas deste estudo um sentimento de impotência e aprisionamento.

Ao se aplicar o método hermenêutico, foram identificadas palavras e expressões chaves que intitularam as categorias analisadas: 1) "Aí eu posso entrar?": a inserção no mundo do trabalho; 2) "Nutricionista tem obrigação de estar dentro do Índice de Massa Corporal (IMC) certo"; 3) "Aqui nutricionista obesa não pode ficar": o sentido de fracasso na profissão, 4) Os profissionais de saúde estão prontos para tratar a obesidade?

\section{"Aí eu posso entrar?": a inserção no mundo do trabalho}

No mundo do trabalho, a obesidade tem conotação negativa e interfere na qualidade de vida do trabalhador, deixando-o susceptível à discriminação e ao preconceito em virtude da não adequação aos requisitos exigidos ${ }^{15}$.

Ao serem questionadas sobre o preconceito do empregador contra a obesidade marcada no corpo, as entrevistadas afirmam que nas suas experiências não houve resistência:

Não (fisionomia séria e perde a leveza da expressão facial de antes, como se não estivesse mais à vontade para falar). ... Claro que sempre diz: "nutri não pode comer assim", mas eu finjo que não é comigo. Eu finjo que não ouço (silêncio e dá de ombros) (Beatriz, 30 anos).

No concurso público a capacidade técnica falou mais alto. Mas sei que na clínica e hospitais particulares não pode ser gordo. ... A nutricionista obesa é rechaçada (Carol, 39 anos).
Não tenho problema porque sou servidora pública. Na iniciativa privada sou professora de disciplina que não tem relação estrita com clínica, então (pausa a fala), passa (dá de ombros) (Alice, 39 anos).

Não tive problema. Na universidade os critérios para ingressar são outros (Candice, 57 anos).

Na hora da contratação não tive problema porque viram que eu era competente. ... Mas na hora de ir para mídia como imagem da empresa, quem ia era uma colega magra (Diná, 49 anos) (Grifos nossos).

A obesidade é evidenciada por Carol e Diná como uma doença que demarca o lugar onde se pode circular - como um processo de higiene ocupacional (linguagem metafórica). Nesses espaços de trabalho, o obeso sente seu problema a partir da visibilidade pejorativa que é dada ao corpo gordo. Há um sistema de valores numa dada comunidade, e aquele que não consegue preencher os requisitos "da normalidade corporal" ver-se-á, pelo menos em alguns momentos, como indigno, incompleto e inferior?

Essa ideia é reforçada quando se afirma que a obesidade parece estar se transformando em uma nova categoria de deformidade ${ }^{16}$ ao se configurar como fator determinante da inserção no mundo do trabalho, conforme revela a fala de Carol ao mencionar o trabalho em algumas instituições privadas. Entretanto, é revelado nas narrativas de Candice e Alice que a instituição pública se afirma como um espaço que não legitima a estigmatização no acesso em função da isonomia do concurso.

A narrativa a seguir mostra que Beatriz resiste em confrontar essa realidade que está ecoando na sua vida. Quando interrogada sobre a dificuldade em encontrar emprego, ela revela:

Se tive, ninguém me disse. Fiz muitas entrevistas de emprego e em algumas eu não consegui entrar, mas ninguém disse 
que era por causa disso (referindo-se à obesidade). Muito embora durante a prova da Residência (em nutrição clínica) uma professora da banca me perguntou por que eu não fazia uma bariátrica. Eu posso morrer com 300 anos, mas eu nunca vou esquecer esse dia (Beatriz, 30 anos) (Grifos nossos).

Ela narra sua história, fala com profundidade e sofrimento sobre o que viveu, revelando o estigma ${ }^{7}$ da obesidade entre seus pares. Nessas palavras, ela mostra como foi ferida pelo sistema e traz um sentido para o acontecimento que ultrapassa o que se vê na descrição dos fatos.

\section{"Nutricionista tem obrigação de estar dentro do IMC certo"}

As narrativas revelam que o mundo do trabalho para essas nutricionistas obesas é desafiador e, muitas vezes, limita sua atuação. Sobre isso, as entrevistadas acreditam que a profissão impõe limites ao corpo e ao seu comportamento alimentar, conforme se vê abaixo:

Como é que você com excesso de peso vai fazer orientação para emagrecimento? Com obesidade, para o consultório eu não podia retornar porque eu estava diferente na minha prática (Sônia, 41 anos).

A obesidade vai influenciar na vida de qualquer trabalhador, e da nutricionista ainda mais, por ter o conhecimento e a obrigação de ser magro e estar dentro do IMC certo (Eduarda, 37 anos).

Se for nutricionista esportiva tem que ser sarada (Amaly, 33 anos) (Grifos nossos).

No caso de Sônia, foi ela quem apontou em si mesma uma incoerência que a impedia de exercer a profissão diante do seu corpo gordo. Para essa nutricionista, o julgamento não veio do outro, mas de si. Para as entrevistadas, sua atuação profissional impõe um dever moral de manter o corpo em padrões antropometricamente adequados. A obesidade é caracterizada por elas mesmas como transgressão de uma norma, desordem moral que não pode ser aceita. A doença é um incômodo e deposita na pessoa uma carga pejorativa ${ }^{7}$ que ocasiona sofrimento. Assim, o obeso vive um profundo sentimento de inferioridade moral ${ }^{17}$.

As narrativas vêm afirmar que o mundo do trabalho do nutricionista perpassa pelo uso de si, do corpo que habita, sendo um exercício constante conectar a teoria aprendida por ocasião da sua formação à sua prática. Nesse sentido, em consonância com relatos anteriores das colegas, Diná reafirma que suas vivências produzem em si sentimento de menos valia, quando diz:

Tive uma coordenadora nutricionista que falava que não conseguia acreditar que eu era nutricionista e gorda (Diná, 49 anos) (Grifos nossos).

O sofrimento vivido por ela advém do sentimento de desqualificação atribuída pelo outro ao não reconhecer a importância do seu trabalho, podendo acarretar no adoecimento físico e psíquico da nutricionista ${ }^{18}$. Esse fato também é presente na vida de outras mulheres, que revelam situações pela quais passaram no trabalho e nas quais se sentiram menosprezadas, constrangidas e desrespeitadas:

(no ambiente de trabalho) já ouvi comentários desagradáveis de professor sobre essa relação do nutricionista com o peso. Foi uma agressão para mim (Sônia, 41 anos).

Os colegas (professores) diziam que eu não podia ser nutricionista gorda daquele jeito. Nutricionista é cruel, principalmente se nunca foi gordo - acha que dieta todo mundo pode fazer (Carol, 39 anos).

Depois que assumi alguns cargos de liderança na nutrição isso (referindo-se à obesidade) me incomoda. Colega cobra mesmo! (Jéssica, 47 anos) (Grifos nossos). 
Os relatos dessas mulheres sobre situações vividas no cotidiano do trabalho apontam o sofrimento em suas existências dado que o acesso às informações científicas não Ihes garantiu a possibilidade de ter um corpo esguio. Sem a intenção de generalizar os achados para toda a categoria profissional, as entrevistadas revelaram que se sentem discriminadas pelos seus pares ao constatarem que não estão inseridas numa categoria profissional formada por pessoas que compreendem suas dificuldades diante do fenômeno da obesidade.

Dados sobre a inserção profissional apontam que a área com maior percentual de atuação é a nutrição clínica $(41,7 \%)$, seguida da área de alimentação coletiva $(32,2 \%)^{19}$. Mortoza ${ }^{3}$ aponta que a formação do nutricionista, à época da criação da profissão, tinha ênfase em nutrição clínica e alimentação coletiva com vertente biomédica fortemente marcada e reduzido foco na dimensão social, o que permite inferir que o cenário encontrado pelas entrevistadas desse estudo seja reflexo desses achados. Segundo essa autora $^{3}$, mesmo após reformas curriculares dos cursos de graduação em nutrição, a formação ética e humanística aparece como item pouco valorizado pelas instituições na divulgação dos cursos. Marcelino \& Patrício ${ }^{20}$ recomendam que as instituições formadoras reforcem em seu currículo a atuação interdisciplinar capaz de contribuir para remodelar as práticas de saúde, particularmente aquelas relacionadas à alimentação e aos demais hábitos e estilos de vida promotores da obesidade.

\section{"Aqui nutricionista obesa não pode ficar": o sentido de fracasso na profissão}

A pesquisa realizada mostra que, para a nutricionista, há um impedimento de se estabelecer em alguns postos de trabalho que são determinados pela obesidade. Autores apontam a obesidade como prejuízo que repercute nas relações de trabalho, desde a seleção até a permanência pela relação com o desempenho da função ${ }^{21}$. Sobre isso, as nutricionistas relataram ter vivido constrangimento:
A coordenadora disse que cortaria meu salário ou me tiraria de sala de aula para ver se eu emagrecia. E dizia que para falar de saúde com aquele corpo não podia! Várias vezes eu ouvi e vi olhares que diziam: "Como é que você nutricionista está com esse corpo?". Ouvi isso dos colegas de profissão. Professores (Carol, 39 anos).

... Fui demitida porque não ficava bem para uma empresa de alimentação ter uma nutricionista gorda (Rita, 62 anos).

Nas comunidades as pessoas não verbalizam, mas está dito no olhar ( $f a z$ gesto com a mão na direção do rosto): Que nutricionista gorda é essa? No trabalho aprendi a me blindar e acabo não escutando observações a respeito do meu corpo obeso (Alice, 39 anos).

Nunca tive problema de empregador dizer: Ah, ela é gorda (ênfase).... Tenho uma colega que era obesa e fez cirurgia (redutora) de estômago e isso melhorou muita coisa na vida dela, inclusive essa questão de emprego (Grazy, 42 anos) (Grifos nossos).

Para essas entrevistadas, a obesidade é vista pelo empregador como uma incapacidade da nutricionista representar sua formação profissional. Essa abordagem da chefia imediata parece ter provocado em Carol um sentimento de ofensa, tristeza e revolta por encontrar dificuldades no âmbito sócio-ocupacional.

Os fatos vividos pelas entrevistadas revelam que o preconceito sofrido por ter um corpo gordo está fortemente marcado em suas existências. No relato de Rita e Carol, foi o outro que julgou serem elas incapazes para assumir sua função estando obesas.

Cibeira et al. ${ }^{21}$ afirmam que é importante aprofundar interpretações relativas ao corpo obeso e como isso pode influenciar pessoas a modificarem radicalmente seus corpos através da submissão à cirurgia bariátrica. Outros estu- 
$\operatorname{dos}^{20,22}$ mostram que a cirurgia bariátrica é o recurso final adotado pelos sujeitos para tratar a obesidade.

Nesta pesquisa com nutricionistas obesas, houve relatos sobre as trajetórias em busca pelo emagrecimento em que a decisão pela intervenção cirúrgica foi provocada pelo sentimento de fracasso na profissão. Foi o caso de Rita, que, após ser demitida em decorrência da sua obesidade, passou pelo procedimento.

Depois da demissão devido à obesidade tomei a decisão mais difícil de minha vida: fiz a cirurgia de redução de estômago, mas estou engordando de novo, e se tiver um jeito de corrigir tudo com outra cirurgia, eu faço! (Rita, 62 anos) (Grifos nossos).

A obesidade representa a dificuldade para o trabalho, e, nessa perspectiva, pesquisa realizada com pacientes obesos submetidos à cirurgia bariátrica apontou melhoria na inserção no trabalho após emagrecimento decorrente dessa intervenção ${ }^{4}$. Na experiência dessas nutricionistas, fica evidente que a obesidade é um obstáculo para inserção e/ou permanência em espaços de trabalho.

A obesidade está presente nas diversas categorias profissionais ${ }^{4}$, inclusive entre os trabalhadores de enfermagem, como encontrado em estudo recente ${ }^{23}$, com um elevado percentual de excesso de peso, o que mostra que o conhecimento técnico científico sobre possíveis agravos à saúde decorrentes do excesso de peso não os fazia mudar o comportamento alimentar e o estilo de vida. Para as nutricionistas obesas, este é um problema físico e social, cuja solução não está apenas no saber técnico, havendo influência dos determinantes sociais.

Pode-se afirmar que a cura da obesidade é desafiadora, em especial para o nutricionista, conforme revelado a seguir:

Está muito difícil modificar essa realidade que estou vivendo. Eu não consigo fazer dieta! Hoje almocei lasanha e a sobremesa foi brigadeiro. Estou trabalhando sem descanso faz dias e a comida é uma compensação. Eu queria ser magra porque é complicado você ter que provar para a sociedade. É muito difícil (Beatriz, 30 anos).

Às vezes, pessoas na rua queriam que eu emagrecesse e me davam dicas de dieta da revista (Jéssica, 47 anos) (Grifos nossos).

Beatriz tem sede e fome de compreensão. Denuncia que se sente desvalorizada pelo sistema social por ter o corpo fora do padrão exterior ditado pela sociedade. O corpo feminino experimenta uma pressão para (re)configurar-se à leitura do belo 24

Os relatos mostram como o corpo gordo incomoda a sociedade por estar fora do padrão normal, não estar belo e saudável conforme as demandas da sociedade moderna contemporânea ${ }^{25-27}$. Assim, ao considerar o corpo como inscrição de feminilidade, afirma-se ainda que as mulheres podem conseguir mais êxito no profissional quando cuidam do corpo e da beleza ${ }^{16}$.

O ideal de beleza pautado no corpo magro como é vigente na atualidade tem oprimido nutricionistas obesas e provocado uma ruptura em sua identidade profissional. Mesmo com a credencial oportunizada pela academia, Beatriz será sempre julgada como culpada por sua obesidade, e, nesse sentido, não é tarefa fácil estabelecer relações sociais saudáveis.

Este estudo reafirma que o sujeito com um corpo considerado gordo pela sociedade sofre interferências na sua vida cotidiana porque é visto como insucesso, o que incita a necessidade de um "policiamento" de si na tentativa de garantir a permanência no trabalho.

Os achados vêm reafirmar que a obesidade é um grave problema de saúde pública que se configura como um desafio para os profissionais de saúde e precisa ser levado em conta pelos programas e políticas de saúde no Brasil, uma vez que os resultados revelam que a obesidade interfere na vida do trabalhador ${ }^{3}$. 


\section{Os profissionais de saúde estão prontos para tratar a obesidade?}

Pesquisa evidencia que a obesidade é fonte de frustração para profissionais de saúde quando se deparam com a baixa adesão e o abandono do tratamento pelos pacientes antes da cura $^{28}$. Com isso, há uma responsabilização do paciente obeso pelos fracassos nas tentativas de emagrecimento, o que deflagra a incapacidade das ciências biomédicas em tratar a obesidade ${ }^{3} \mathrm{e}$ reforça o estigma da obesidade na sociedade.

Teixeira et al. ${ }^{29}$ avaliaram o conhecimento de profissionais de saúde acerca da obesidade e investigou as contribuições da formação acadêmica no desenvolvimento de competências para o enfrentamento desse problema. Os achados revelam crenças ambivalentes e atitudes negativas dos profissionais perante os obesos com tendência à culpabilização do doente, ao tempo que apontam também uma preparação acadêmica insuficiente de algumas categorias profissionais para tratar a doença devido a lacunas de conhecimento relativas aos aspectos nutricionais.

Sobre isso, Carol questiona as ferramentas apreendidas na formação profissional e sua suficiência ao olhar para as pessoas:

Nutricionista só quer saber de medir prega. ... É difícil ser magro. Não é só você tirar a comida e colocar para fazer exercício (chora). Se fosse só isso, eu saberia muito bem o que fazer para emagrecer (Carol, 39 anos) (Grifos nossos).

Para ela, a obesidade necessita ser compreendida extramuros dos consultórios e ir além das teorias produzidas pelos estudos que se pautam na dimensão biológica9 ${ }^{9}$. Nessa perspectiva, estudos sugerem que o tratamento da obesidade deve ter caráter interdisciplinar tendo em vista a ineficácia dos tratamentos centrados no conhecimento específico de uma categoria profissional ${ }^{30,31}$.

Pesquisa realizada com nutricionistas e educadores físicos sobre conhecimentos e con- dutas diante da obesidade mostrou que grande parte dos profissionais está em desacordo com o que é preconizado pelas diretrizes no tratamento dessa enfermidade ${ }^{32}$. Os nutricionistas dominam algumas condutas técnicas para a perda de peso, mas ainda não estão preparados para ampliar estratégias no tratamento da obesidade.

Na visão das entrevistadas deste estudo, a nutricionista trata o paciente pautado estritamente no saber técnico:

Eu já consultei nutricionistas e elas só querem saber de cálculo, de técnica, de contar calorias. Não olham para a pessoa por inteiro. Calcular dieta é fácil. Difícil é uma nutricionista - principalmente se for magra e nunca tiver sido gorda -, entender o que um obeso passa (Diná, 49 anos) (Grifos nossos).

Diná afirma que a abordagem puramente biomédica que experimentou nas tentativas de emagrecer e que costumeiramente são utilizadas por nutricionistas em seu cotidiano de trabalho não vão oferecer resultados promissores. Para ela, o paradigma biológico da nutrição deve fazer uma interlocução com as ciências sociais para que se possa pensar numa perspectiva de cuidado integral.

\section{O currículo de formação de nutricionista precisa ser modificado}

Investigando a percepção da obesidade por nutricionistas a partir de publicações teóricas e analisando os conteúdos disponíveis nos textos utilizados nas instituições de ensino superior no Brasil, uma pesquisadora ${ }^{3}$ mostrou que a literatura científica está principalmente pautada: a) na repreensão ao paciente pelo profissional; b) na crença de que o paciente deve ser capaz de ter autodisciplina, paciência e perseverança no tratamento; c) em técnicas de emagrecimento (dietas, medicamentos, modificações comportamentais e atividade física) isoladas que não dão conta de reverter o excesso de peso, d) na ideia de que 
apesar de a perda de peso ser difícil de ser atingida é imperioso alcançá-la.

A formação do nutricionista perpassa por conteúdos essencialmente biológicos, conforme afirmam as entrevistadas Carol e Diná. Uma publicação aponta que a formação dos profissionais de saúde deve incluir conhecimentos relacionados às ciências humanas e sociais, de modo a debater amplamente a dicotomia existente com as ciências naturais ${ }^{33}$. Nessa perspectiva, as nutricionistas entrevistadas expõem sua vivência com a falta de humanização na abordagem feita por seus pares, como se pôde observar anteriormente em seus relatos.

Diná interpreta a necessidade de debater a formação profissional e sugere a intensificação de disciplinas que aproximem esses sujeitos da compreensão favorecida pela abordagem proposta pelas ciências sociais em saúde. Sobre isso, diz:

\section{O currículo de formação do nutri- cionista precisa ser modificado. Será que ninguém vê a nutricionista mera- mente prescritora fracassando? E que com esse tratamento o obeso vai fracassar na dieta e isso vai refletir em outras esferas da vida? (Diná, 49 anos) (Grifos nossos).}

Ela revela que as nutricionistas para tratar obesidade adotam um tratamento dietoterápico para os pacientes obesos que evidencia o fracasso das propostas, recomendando que as práticas de atendimento clínico sejam revistas pelos seus pares. Desse modo, é preciso ultrapassar o ensinamento de técnicas do campo específico da nutrição, permitindo compreender a importância, por exemplo, do estilo de vida e do ambiente na formação dos hábitos alimentares dos sujeitos.

A antropologia e a sociologia ficam à margem no processo de formação do nutricionista ${ }^{34,35}$. Outro estudo ${ }^{36}$ corrobora esse pensamento ao afirmar que "as ciências biológicas se interessam mais pelas propriedades e funções dos alimentos do que pelos indivíduos, e as ciências sociais, ao contrário, têm interesse pelas pessoas que comem e os sistemas alimentares construídos" (p.110).
Em consonância com os estudos apresentados, o Ministério da Educação ${ }^{37}$ propõe perfil de formação generalista, humanista e crítica. As diretrizes curriculares preveem que, ao serem realizadas intervenções na área de alimentação e nutrição, apliquem-se conhecimentos com visão holística do ser humano integrando conteúdo curricular das Ciências Sociais, Humanas e Econômicas.

Nesse sentido, deve-se incluir a compreensão dos determinantes psicossocioculturais, econômicos, ecológicos, éticos e legais, a comunicação nos níveis individual e coletivo do processo saúde-doença de modo que o nutricionista tenha atitudes e valores orientados para a cidadania e para a solidariedade ${ }^{37}$.

Para Diná, a interação nutricionista-sujeito obeso precisa de transformação. Do mesmo modo, Carol concorda que as técnicas de avaliação nutricional fazem parte de uma tecnologia de cuidado que não favorece a aproximação entre os atores sociais envolvidos e distancia ainda mais o sujeito obeso da terapêutica nutricional.

Ao falar com os pacientes obesos, as nutricionistas entrevistadas entendem a necessidade da humanização e tentam evitar constrangimentos:

Eu sempre tive uma relação muito humana com os pacientes. Isso fez o problema (obesidade) abstrair, sublimar. Eu sentia isso... (Carol, 39 anos).

Tem a questão do visual e pode acontecer de eles terem um pouco de falta de credibilidade. Mas também tem aquela coisa de eu receber as pessoas sempre sorrindo, de ser muito acolhedora. Talvez por isso não tenha tido esses embates (Beatriz, 30 anos) (Grifos nossos).

O ser humano é vulnerável e está exposto a múltiplos perigos, nesse caso, ser agredido, fracassar ${ }^{17}$. No entanto, uma vez consciente das situações-limite com as quais pode deparar-se, busca soluções para combater a insegurança visando proteger-se. Os relatos apresentados nes- 
te estudo, refletem a aflição das protagonistas do estudo e mostram a fragilidade da identidade profissional decorrente do corpo gordo das nutricionistas.

\section{CONSIDERAÇÕES FINAIS}

A obesidade como estigma na profissão de nutricionistas tem comprometido a saúde física e mental das protagonistas deste estudo, revelando sua necessidade expressa do sentimento de pertencimento na categoria profissional.

Conforme objetivo desta pesquisa, identificou-se que as nutricionistas obesas apontam o potencial estigma da obesidade no mercado de trabalho, enfatizando o campo da clínica. A obesidade apresenta-se neste estudo como uma deformidade que não cabe na profissão.

As entrevistadas vivenciaram o estigma no trabalho e situações de sofrimento nas relações sociais por seu corpo representar uma inversão de valores normativos da nutrição e de uma sociedade lipofóbica que desaprova a nutricionista obesa.

Este estudo não pretende representar a categoria profissional, entretanto as nutricionistas entrevistadas sugerem que os profissionais devem superar o discurso tecnicista da academia e compreender que conhecer a singularidade do sujeito a ser cuidado tem importância terapêutica. Debater a formação do nutricionista que atua prioritariamente com caráter de prescrição e normatização de corpos é uma oportunidade de repensar a prática profissional.

A aproximação das ciências da saúde com as ciências sociais potencializa a compreensão dos limites e as possibilidades do corpo. Nesse sentido, este estudo tentou instigar a compreensão sobre a nutricionista obesa nas suas relações de trabalho e ampliar esse debate.

\section{OLABORADORES}

KL ARAÚJO participou da concepção, na coleta e análise dos dados e na redação do artigo. PGL PENA e MCS FREITAS colaboraram na análise dos dados, na redação e na revisão do artigo. RW DIEZ-GARCIA colaborou na redação e na revisão do artigo.

\section{REFERÊ NCIAS}

1. Campos GWS. Apresentação. In: Trabalhador da saúde: muito prazer! Protagonismo dos trabalhadores na gestão do trabalho em saúde. ljuí: Unijuí; 2007.

2. Santos SF, Salles AD. Antropologia de uma academia de musculação: um olhar sobre o corpo e um espaço de representação social. Rev Bras Educ Física Esporte. 2009; 23(2):87-102.

3. Mortoza AS. A obesidade como expressão de questão social: nutrição e estigma [doutorado]. Brasília: Universidade de Brasília; 2011.

4. Mariano MLL, Monteiro CS, Paula MAB. Cirurgia bariátrica: repercussões na vida laboral do obeso. Rev Gaúcha Enferm. 2013; 34(2):38-45.

5. Canguilhem G. O normal e o patológico. $7^{\mathrm{a}} \mathrm{ed}$. Rio de Janeiro: Forense Universitária; 2011.

6. Fazendo Gênero 8: Corpo, Violência e Poder. O corpo como lócus de poder: articulações sobre gênero e obesidade na contemporaneidade. Florianópolis: UFSC; 2008 [acesso 2013 jan 12]. Disponível em: http://www.fazendogenero.ufsc.br/8/sts/ST39/ Meurer-Gesser_39.pdf

7. Goffman E. Estigma: notas sobre a manipulação da identidade deteriorada. Rio de Janeiro: LTC Editora; 1988.

8. Poulain JP. Sociologias da alimentação: os comedores e o espaço social alimentar. Florianópolis: UFSC; 2006.

9. Brasil. Ministério da Saúde. Obesidade. Cadernos de Atenção Básica, $n^{\circ} 12$. Série A. Normas e Manuais Técnicos. Brasília: Ministério da Saúde; 2006.

10. Helman CG. Cultura, saúde e doença. $5^{a}$ ed. Porto Alegre: Artmed; 2009.

11. Cavechia LA, Bustamante PG, Correia, JR. Diagnóstico dos agricultores familiares feirantes da comunidade de Água Boa II, Norte de Minas Gerais. Comun Téc Cent Nac Recur Genet Biotecnol. 2008; (179).

12. Bibeau G, Corin E. Beyond textuality: Ascetism and violence in antropological interpretation. Berlin: Mouton de Gruyter; 1995.

13. Gadamer HG. Verdade e método. Petrópolis: Vozes; 1997. 
14. Minayo MCS. O desafio do conhecimento: pesquisa qualitativa em saúde. $12^{a}$ ed. São Paulo: Hucitec; 2012.

15. Paixão MPCP, Paixão SJP, Franco LR. Obesidade como fator de risco para acidentes no trabalho. Rev Saúde Pesqui. 2009; 2(3):379-86.

16. Santos LAS. Da anorexia à obesidade: considerações sobre o corpo na sociedade contemporânea. In: Diez-Garcia RW, Cervato-Mancuzo AM, coordenadores. Nutrição e metabolismo: mudanças alimentares e educação nutricional. Rio de Janeiro: Guanabara Koogan; 2012.

17. Torralba Roselló F. Antropologia do cuidar. Petrópolis: Vozes; 2009.

18. Dejour C. A loucura do trabalho: estudo de psicopatologia do trabalho. São Paulo: Cortez-Oboré; 1992.

19. Conselho Federal de Nutricionistas. Perfil da atuação profissional do nutricionista no Brasil. Brasília: Conselho Federal de Nutricionistas; 2006 [acesso 2013 nov 6]. Disponível em: http://www. cfn.org.br/novosite/pdf/pesquisa.pdf

20. Marcelino LF, Patrício ZM. A complexidade da obesidade e o processo de viver após a cirurgia bariátrica: uma questão de saúde coletiva. Ciênc Saúde Colet. 2011; 16(12):4767-76.

21. Cibeira GH, Alves BS, Surita LE, Muller C, Felippe FML, Friedman R. Representação social da obesidade. In: XXIII Jornada de Nutrição do Hospital de Clínicas de Porto Alegre, 2003 [acesso 2013 nov 13]. Disponível em: http://www.lume.ufrgs.br/ bitstream/handle/10183/49148/000404837.pdf? sequence $=1$

22. Castro MR, Ferreira MEC, Carvalho RS, Ferreira VN, Pereira HAC. Cirurgia bariátrica: a trajetória de mulheres obesas em busca do emagrecimento. HU Rev. 2010; 36(1):29-36.

23. Silveira CDS, Urbanetto JS, Silva PC, Magnago TSBS, Poli-de-Figueiredo CE. Perfil de sobrepeso e obesidade em trabalhadores de enfermagem em unidades de cuidado intensivo e emergência. Rev Ciência Saúde. 2013; 6(3):157-62.

24. Freitas MCS. Mulher ligth: corpo, dieta e repressão. In: Ferreira SL, Nascimento ER, organizadores. Imagens da mulher na cultura contemporânea. Salvador: UFBA; 2002.

25. Silva AC, Ferreira JT. Gordura corporal: entre a patologização e a falência moral. Physis. 2013; 23(1):289-96.

26. Vargas EGA. A influência da mídia na construção da imagem corporal. Rev Bras Nutr Clín. 2014; 29(1):73-5.
27. Kanno P, Rabelo M, Melo GF, Gioani A. Discrepâncias na imagem corporal e na dieta de obesos. Rev Nutr. 2008; 21(4):423-30. http//:dx.doi.org/ 10.1590/S1415-52732008000400006

28. Silva CPG, Bittar CML. Fatores ambientais e psicológicos que influenciam na obesidade infantil. Rev Saúde Pesqui. 2012; 5(1):197-207.

29. Teixeira FV, Pais-Ribeiro JL, Maia ARPC. Crenças e práticas dos profissionais de saúde face à obesidade: uma revisão sistemática. Rev Assoc Med Bras. 2012; 58(2):254-62.

30. Santos PLS. Efeitos de intervenção interdisciplinar em grupo para pessoas com diagnóstico de sobre peso ou obesidade [mestrado]. Brasília: Universidade de Brasília; 2010.

31. Oliveira LH, Almeida P. Obesidade: aspectos gerais de fatores, tratamento e prevenção. Rev Voos. 2012; 4(2):34-46.

32. Silva CC, Bento SAA, Gralha S. Nível de conhecimento e principais condutas de nutricionistas e educadores físicos frente à obesidade. Rev Bras Obes Nutr Emagr. 2007; 1(2):1-15.

33. Canesqui AM, Diez-Garcia RW. Ciências sociais e humanas nos cursos de nutrição. In: Canesqui AM, Diez-Garcia RW, organizadores. Antropologia e nutrição: um diálogo possível. Rio de Janeiro: Fiocruz; 2005.

34. Silva DO. Reflexões conceituais e de profissionais de saúde sobre a promoção da alimentação saudável. In: Nutrição e metabolismo: mudanças alimentares e educação nutricional. Rio de Janeiro: Guanabara Koogan; 2012.

35. Santos LAS. Educação alimentar e nutricional no contexto da promoção de práticas alimentares saudáveis. Rev Nutr. 2005; 18(5):681-92. http//:dx. doi.org/10.1590/S1415-5273205000500011

36. Pons SC. Pontos de partida teórico-metodológicos para o estudo sociocultural da alimentação em um contexto de transformação. In: Canesqui AM, Diez-Garcia RW, organizadores. Antropologia e nutrição: um diálogo possível. Rio de Janeiro: Fiocruz; 2005.

37. Brasil. Ministério da Educação. Diretrizes curriculares nacionais dos cursos de graduação em enfermagem, medicina e nutrição. Brasília: MEC; 2001 [acesso 2014 mar 23]. Disponível em: http://portal. mec.gov.br/cne/arquivos/pdf/2001/pces1133_ 01.pdf

Recebido: maio 8, 2015 Versão final: agosto 14, 2015 Aprovado: agosto 24, 2015 
